\title{
Téoros
}

Revue de recherche en tourisme

\section{Regard sur deux tourismes}

\section{Jean-Paul DeSmedt et Marcel Samson}

Volume 8, numéro 1, mars 1989

France-Québec

URI : https://id.erudit.org/iderudit/1080345ar

DOI : https://doi.org/10.7202/1080345ar

Aller au sommaire du numéro

Éditeur(s)

Université du Québec à Montréal

ISSN

0712-8657 (imprimé)

1923-2705 (numérique)

Découvrir la revue

Citer ce document

DeSmedt, J.-P. \& Samson, M. (1989). Regard sur deux tourismes. Téoros, 8(1),

2-2. https://doi.org/10.7202/1080345ar d'utilisation que vous pouvez consulter en ligne.

https://apropos.erudit.org/fr/usagers/politique-dutilisation/ 


\section{Éditorial France-Québec Présentation \\ Regard \\ sur deux \\ tourismes \\ Le tourisme en France \\ et au Québec: \\ un "marché commun" pour les années 1990}

Depuis 20 ans, les relations privilégiées entre le Québec et la France ont donné lieu à diverses manifestations conjointes. S'agissant du tourisme/loisirs, Vétait intéressant de mettre en parallèle la facon dont chacun percoit son développement et fait face à ses obligations. La réalisation du numéro conjoint Téoros/ESpacES se situe dans ce contexte.

Le sommaire est donc éclectique, c'est-à-dire que nous avons voulu donner une vision un tant soit peu comparative sur des aspects qui nous semblent essentiels. Marchés, planifications, offre d'hébergements, évolution des pratiques de loisirs, introduction de nouvelles technologies, formation des cadres ne sont-ils pas les grands enjeux du tourisme/loisirs des années 1990?

Savoir regarder ce qui se passe ailleurs, n'est-ce pas fondamental pour des professionne/s du tourisme?

\section{Jean-Paul DeSmedt \\ Rédacteur en chef, ESpacES \\ Marcel Samson \\ Rédacteur en chef, TÉOROS}

Les rédactions de Téoros et d'ESpacES remercient les sections québécoise et française de l'Office FrancoQuébécois pour la Jeunesse pour leur aide indispensable dans l'élaboration de ce numéro conjoint. Ils remercient également monsieur Jean Pelletier qui fut, pour le Québec, coordonnateur de ce numéro.
Dans le sillage du 20 e anniversaire (1968-1988) des actions de l'Office Franco-Québécois pour la Jeunesse, la revue française ESpacES et son équivalent québecois Téoros ont convenu d'unir leurs efforts pour réaliser un numéro spécial permettant aux analystes, décideurs et autres partenaires des deux communautés de partager leurs visions et perspectives en matiere de développement touristique.

Est-il besoin de rappeler que les cousins de I'Ancien et du Nouveau monde ont depuis les années 1960 tissé des hens d'affaires dans tous les secteurs, relations qui ne cessent de solliciter les investisseurs et de consolider les bases des projets communs. Les dynamiques politiques et économiques (/'Europe de 1992, I'Accord du hibreéchange/ appellent une perspective renouvelée des portes d'entrée sur /'Europe et l'Amérique du Nord. Les flux touristiques entre la France et le Québec sont déjà considerables et devrajent pouvoir être amplifiés au cours de la prochaine décennie. Les enjeux sont importants et nombreux pour une diversité appréciable d'intervenants touristiques et autres intéressés par les retombées des déplacements des touristes et autres voyageurs.

Ce numéro conjoint ESpacES-Téoros est une occasion unique de mieux connaitre et comprendre les defis auxquels les promoteurs et gestionnaires de la France et du Québec auront à faire face. Bonne lecture!

Jean Pelletier

Directeur du Centre d'études du tourisme. 